Birlesik Dünya Arastırma

BD C CENTER

Innovasyon ve Yayınılık Merkezi

\section{Global Journal of Sociology: Current Issues}

Volume 10 , Issue $2,(2020)$ 40-50
Global Journal

of Sociology:

Current Issues

www.gjsoc.eu

\title{
Metaphors in political campaigning - An anthropological linguistics perspective
}

Alia Razia Malik*, National University of Sciences and Technology, 51 Street 92, G-13/1 G 13/1 G-13, Islamabad, Pakistan

\section{Suggested Citation:}

Malik, A. R., (2020). Metaphors in political campaigning - An anthropological linguistics perspective. Global Journal of Sociology: Current Issues. 10(2), 40-50. https://doi.org/10.18844/gjs.v10i2.4753

Received July 25, 2020; revised September 23, 2020; accepted November 25, 2020.

Selection and peer review under responsibility Prof. Dr. Mustafa Gunduz, Cukurova University, Turkey.

${ }^{\circ} 2020$ Birlesik Dunya Yenilik Arastirma ve Yayincilik Merkezi. All rights reserved.

\begin{abstract}
Language is a means of communication in a society. According to linguistic anthropology, a speaker is a social actor who expresses certain ideologies through language. Concepts and ideas, transmitted through language, are part of larger cultural whole in the society. Linguistic anthropology deals with language from a cultural perspective. People represent their mental realities through language which in turn is shaped by culture. Politics is a field of power and dominance. In political discourse, power is exerted through language. Political discourse is to persuade or to motivate the masses. Hence, linguistic choices are important to achieve certain objectives. In Pakistan, the general elections of 2013 were unique in the aspect as it was the first time that one elected democratic government had completed its turn of 5 years and lead towards the next election. Otherwise, the history of Pakistan is marked by incomplete tenures of democratic government and dictatorship. The elections were held on 11 May 2013 in all constituencies of Pakistan. People from all four provinces Punjab, Sindh, Khayber Pakhtoon Khawah, Balochistan, federal area and tribal area had casted their votes.
\end{abstract}

Keywords: First keyword, second keyword, third keyword, forth keyword;

* AdDRESS FOR CORRESPONDENCE: Alia Razia Malik, National University of Sciences and Technology, Islamabad, Pakistan.

E-mail address: Pakistan aliaraziamalik@mcs.edu.pk 


\section{Introduction}

Language is a means of communication in a society. According to linguistic anthropology, a speaker is a social actor who expresses certain ideologies through language. Concepts and ideas, transmitted through language, are part of a larger cultural whole in the society. Linguistic anthropology deals with language from a cultural perspective. People represent their mental realities through language which in turn is shaped by culture. Politics is a field of power and dominance. In political discourse, power is exerted through language. Political discourse is to persuade or to motivate the masses. Hence, linguistic choices are important to achieve certain objectives.

In Pakistan, the general elections of 2013 was unique in the aspect as it was the first time that one elected democratic government had completed its turn of 5 years and lead towards the next election. Otherwise, the history of Pakistan is marked by incomplete tenures of democratic governments and dictatorship. The elections were held on 11 May 2013 in all constituencies of Pakistan. People from all the four provinces Punjab, Sindh, Khayber Pakhtoon Khawah, Balochistan, federal area and tribal area had casted their votes.

\subsection{Theoretical framework}

Political discourse is the field of persuasion and assertion of specific point of views. Language is very important in the political domain and politicians use different rhetoric strategies to create an everlasting impact on the public. Metaphors are the main form of persuasion. The cognitive metaphor theory explains the notion of universal metaphors as a cognitive commonality in human beings (Lakoff \& Johnson). It fails to account for variations. To overcome the limitation of this theory, Foucannier and Turner's model of blended theory of metaphor is added up. The anthropological linguistic view is applied to examine the cultural link of metaphoric expressions in political campaigning. It will also highlight the use of language in relation to the culture of our society. Culture is a system of symbols and is a shared knowledge of the members of the society. Abstract concepts of the culture are communicated through the use of metaphors as 'they are culturally specific mental representation of the world' (Kovecses, 2005).

\subsection{Research questions}

The present study will attempt to focus on following questions:

1. What cultural concepts are manipulated through the use of metaphors in political campaigning?

2. How do these metaphors create particular identities of these political parties?

1. The present study focuses only on one main stream political party in Pakistan.

2. Speeches of the leaders of the political party are analysed. Speeches in political rallies, arguments and slogans are covered.

\subsection{Review of the literature}

Politics is the field of power, authority and dominance is achieved through language. It is not a physical control, rather it is a way to rule the minds of people. Therefore, language plays a vital role in the political domain. Politicians express their ideas, thoughts and opinion via scrutinised use of language. Language use in political sphere is constructed to achieve the desired results that are controlled and authoritative over the public. The importance of language is manifested in the following definition of politics:

A mixture of persuasive techniques, aesthetic norms and political relationships working together in cohesive patterns of motivation activated through speech (Hairman, p. 19). Political speeches are persuasive discourse. A metaphor is a tool to be used by the speaker to elaborate and explain the given concept. They certainly have implied meanings, therefore used as a persuasive tool. Cognitive 
linguistics identifies metaphors as embedded in human thought process. Metaphors are basically the explanation of one term or concept with the help of another concept. The term or concept to be defined is called 'target domain', while the concept used to explain it is called 'source domain'. Source domain has certain characteristic features which are extended to the target domain. So a metaphor contains the 'coherent system of organisation' (Lakoff, 1990). An interpreter understands the meaning with the help of this coherent system of organisation.

Concept domain explains the target domain because there is 'correspondence' between these two. This correspondence is called 'mapping' (Kovesces, 2000, p. 4). But we cannot say that concept $A$ is equal to concept $B$ because there is partial mapping between the two concepts. There are some qualities which are common and evoked by correspondence. Gerard Steen $(1999$, p. 83) describes the same as 'implicit metaphor' and 'explicit metaphor'. In explicit metaphor, the linguistic item is available in the sentence or clause which points to a metaphor, whereas in implicit metaphor the linguistic item is not used rather the meaning is inferred from the context. He uses the example for implicit metaphor as 'praying bird hovering over the crowd' which refers to the helicopter circling the area. The linguistic term 'helicopter' is not used in the sentence but understood by the reader within the context. Kovesces (2000) describes the common categories of source domain as human body, health and illness, animals, plants, buildings, machines, games, sports, movement and direction and common target domains as emotions, desires, morality, thought, society, nation, politics, events, actions etc.

Cognitive linguistic approach describes metaphor as universal phenomena because it is based on the experience of the physical world. But there are metaphoric expressions which are culturally ascribed. Kathryn Allan (2006, p. 175) stresses upon the cultural influence on the choice of source domain in elaboration of target concepts. She takes Foucannier's blending theory to clarify the motivation in interpretation of particular metaphoric term through cultural induce mapping. Similarly, Koller (p. 239) studies metaphor in natural language which reveals the view of metaphor as transcultural, ahistoric phenomenon'.

Gentner (1989) explains the metaphor comprehension on the basis of analogy. He elicits that the structure of one domain is mapped onto the other domain. Through structure-mapping, the receiver applies connected rational knowledge to grasp the given concept. Similarly, Leezenberg (2001, p. 10) advocates that it is the process in which two objects are connected in a particular way and reader or hearer constructs its meaning. It is the capability of cognitive mechanism in which logical meaning is deduced through analogies.

The cognitive linguistic approach describes the comprehension of metaphors through structural similarity through image-schema between target and source domain. This is entrenched in human mind through physical, biological or cultural experience. These factors help to motivate the individual to choose the appropriate source domain which is correlated with target domain.

Similarly, the structural similarity of ontological metaphors is realised. In understanding of target domain an individual gets motivation to apply source B over C or D because this concept of source domain B is rooted in his physical, biological or cultural knowledge. Source domain for metaphors can vary from culture to culture. Sopory (2002, pp. 385-387) elaborates the six advantages of metaphoric language over literal language as pleasure or relief, communicator credibility, reduced counter arguments, resource matching, stimulated elaboration and superior organisation.

Fauconnier (1997) has given the four space theory for metaphor explanation. It works on the basic assumption of two domain approach. He propagates that mapping between two domains, that is target and conceptual domain produces two more domains. Initial two domains give rise to a generic space which explains the meaning in relation to source domain. There is a fourth apace, allied blended space, which is added structure of complex meaning resulting out of three spaces. The meaning is explained through combination, completion and elaboration. Kovecses (p. 7) calls it inference or entailments. 
This approach explains the concept of novel metaphors. Blended space is more creative in a way that meaning of two domains can be extended in any direction with the lines of original two domains. Metaphorical meaning is extended from two domains into resultant two spaces though elaboration and completion (Fauconnier, 1997, p. 156). Context is important in metaphor comprehension. Swinburne (2007). Psychologist's experiments have shown that readers and hearers automatically grasp the intentional meaning of metaphoric concepts within specific contexts but depth of inferences is correlated to their IQ level (Bougher, 2012; Kazmerski \& Blasco, 2003).

Novelty comes in the metaphoric expression through elaboration of metaphoric utilisation. For single target domain there are various source domains which can highlight the different aspects of the target domain. So the reason of selection of particular source domain is dependent on many factors that are 'correlation in experience, perceived structure similarity, structural similarity of basic metaphor and source as the root of the target domain' (Kovecses, p. 88).

Anthropologists argue that the signs and symbols can be explained with the help of metaphors as they are connected with metaphoric process. Beck, Douglas, Edmonson, Fernandez, Levinson, and Loveland (1978, p. 240) describe metaphor as a process to clarify abstract relationship of one domain in terms relationships of more vivid domain. The purpose is to provide... new sudden and striking collocations of references for the sake of the compound effects of contrast, conflict, harmony... or [be] used more simply to modify and adjust emotional tone... through association' Metaphors are systematic and planned which works on analogies. It reveals the world view of the speakers. Therefore anthropologists are interested in its study which can link with the culture of specific society. They are interested in the mental processes and perception of the world. Metaphor is a kind of link between these two. Danesi (2004, p. 152) also takes metaphor as a reflection of 'group thought'. He says that metaphor represent the 'proverbial wisdom' of particular cultural community.

\subsection{Research methodology and sample of the research}

In Pakistan, the 14th general elections were held on 11 May 2013 for provincial and federal assemblies. Political campaign of one of the emergent political party, Pakistan Tehreek-e-Insaaf (PTI) for these elections is covered for the present research. Political campaign started on 27 March 2013 and lasted till 10 May 2013.

The purpose of the research is to analyse the metaphors in political discourse of the poll drive of 2013 election; therefore, the extracts are selected which contain the metaphors and metaphoric expressions. The speeches of political leader are focused through metaphor analysis. Speeches are the form of verbal data. It is natural language data generated by politicians. The data is collected through internet search engine. Speeches which are telecasted on Television and available on You Tube are noted down. The resultant text is annotated to point out the metaphors and metaphoric expressions.

The framework for the research is based on the application of 'Conceptual Theory of Metaphor' given by Lakoff and Johnson and 'Blending Theory' by Fauconnier and Turner. Marked lexical items in this process are analysed on the basis of the 'two domain approach'. This approach defines metaphor as a process of comprehension in which one concept (target) is understood in terms of another concept (source) which is more concrete and vivid. There is cross-mapping in these two concepts which brings into light the underlying properties common in these two domains. The cross-domain mapping is partial and motivated by the shared knowledge of user of the language being a part of particular speech community. Conventional metaphors are studied by two-domain approach of metaphor.

Blending theory also assume partial mapping between the target and source domain which results in 'generic space'. Generic space then leads to the more abstract and complicated structure in the type of 'blend'. The resultant 'blend' is formed through three step process that are 'composition', 'completion' and 'elaboration' (Fauconnier, 1997). In composition a new frame work is set forth by cross-mapping of two concepts which is not the part of individual concept. The second process of 
completion is achieved with the help of previous knowledge, life and cultural experiences. All these factors contribute to the formation of more complex form of 'blend'. This final construction of 'blend' is then can be elaborated for its new and more complex meaning. Novel metaphors are examined in the light of blending theory. The analysis drawn is then related to the anthropological linguistic perspective of the language used in Pakistani society. It highlights the cultural import of source domains used in metaphoric expressions.

\section{Analysis}

\subsection{Political campaign of PTI}

PTI has participated in the present political contest as a third emerging political force in Pakistan. Its campaign is guided by the chairman Imran Khan. He is the former cricketer and ex-captain of the Pakistani cricket team. The party basically aims at mobilising the youth of Pakistan.

\subsection{Use of metaphors}

Various interest and concerns lead to the innovation in metaphoric expressions as in the case of PTI. They use new expressions of sports to target the youth. In Pakistani culture, cricket is a popular game especially among youth. Leader of PTI, being a former cricketer deliberately uses such terminology. Diverse metaphoric expressions of PTI are grouped into following categories.

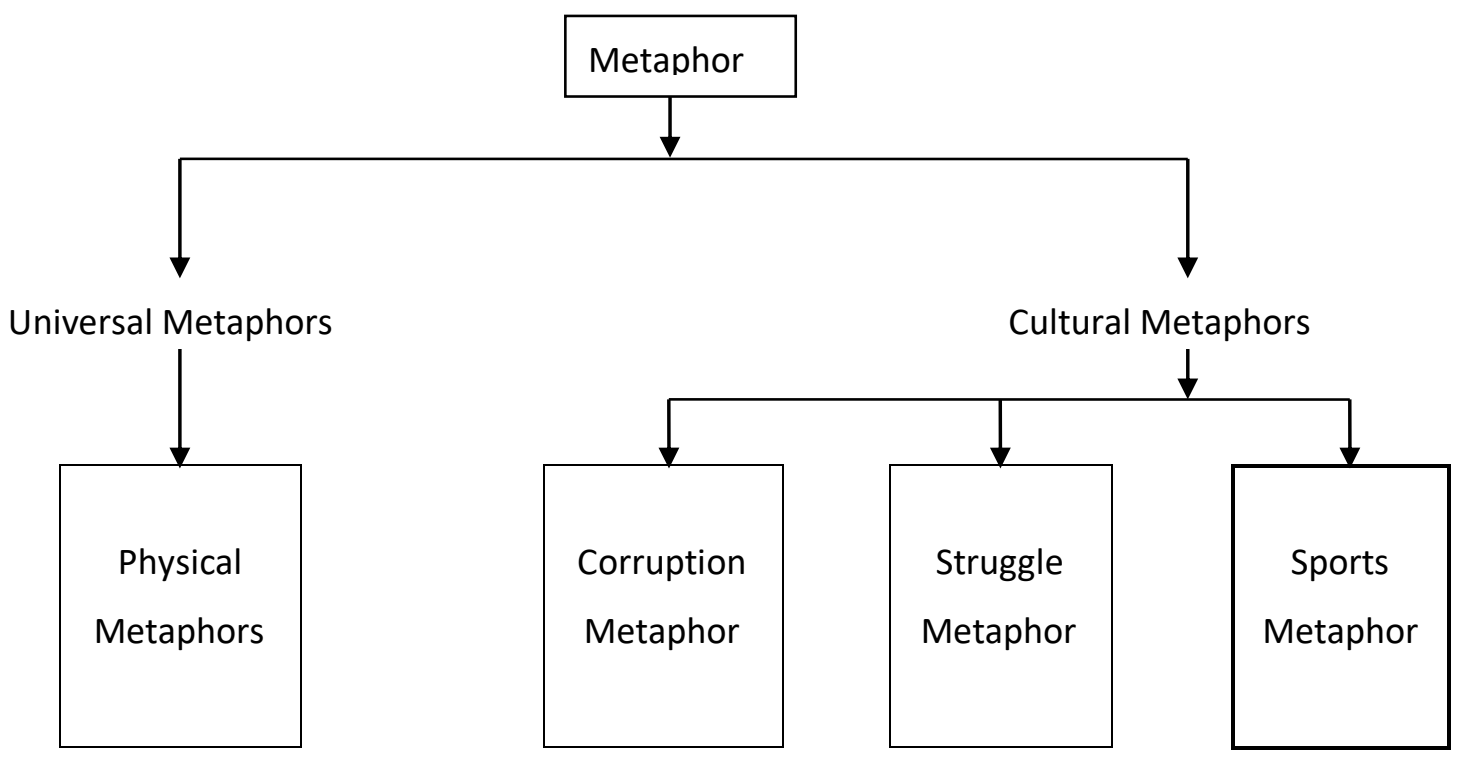

\subsection{Physical metaphor}

Party leader Imran Khan asserted that Pakistani youth and general public is the source of power for his party. He repeatedly used the word 'Tsunami' for the force of his party. Tsunami is a physical phenomenon related to geology. The word originated from Japanese language and a combination of two words 'tsu' means 'harbour' and 'nami' means wave. Tsunami is caused by earthquake and gravitational influences in ocean which results in high tidal waves. The structural metaphor associate the impact and effect of tsunami with the influence of PTI on the political scenario of Pakistan is further appeared in blend. It will eliminate and eradicate the old system from country. 
[Awam ka thathe marta samandar.... Tsunami ki lehrain jo Badshahi Masjid ke minaron ko choo rahi hain.]

'Great Ocean of people ....(like) waves of Tsunami which is touching the minarets of Badshahi

Mosque.'

[Ab tsunami ki bari hai.] 'Now it's the turn of Tsunami.'

[Mujhe khushi hai ke tsunami ka aaghaz ho gaya hai.] 'I am happy that Tsunami has started.' [Naujawanon! tsunami ke lye tayar ho jao. ] 'Young people! Be prepared for Tsunami.'

Target domain PTI and source domain tsunami are cross-mapped to reveal the force of the party. General public and youth are on front line to bring change in the country. In blend, the concept is extended to bring positive change and overall transformation and revolution in political system.

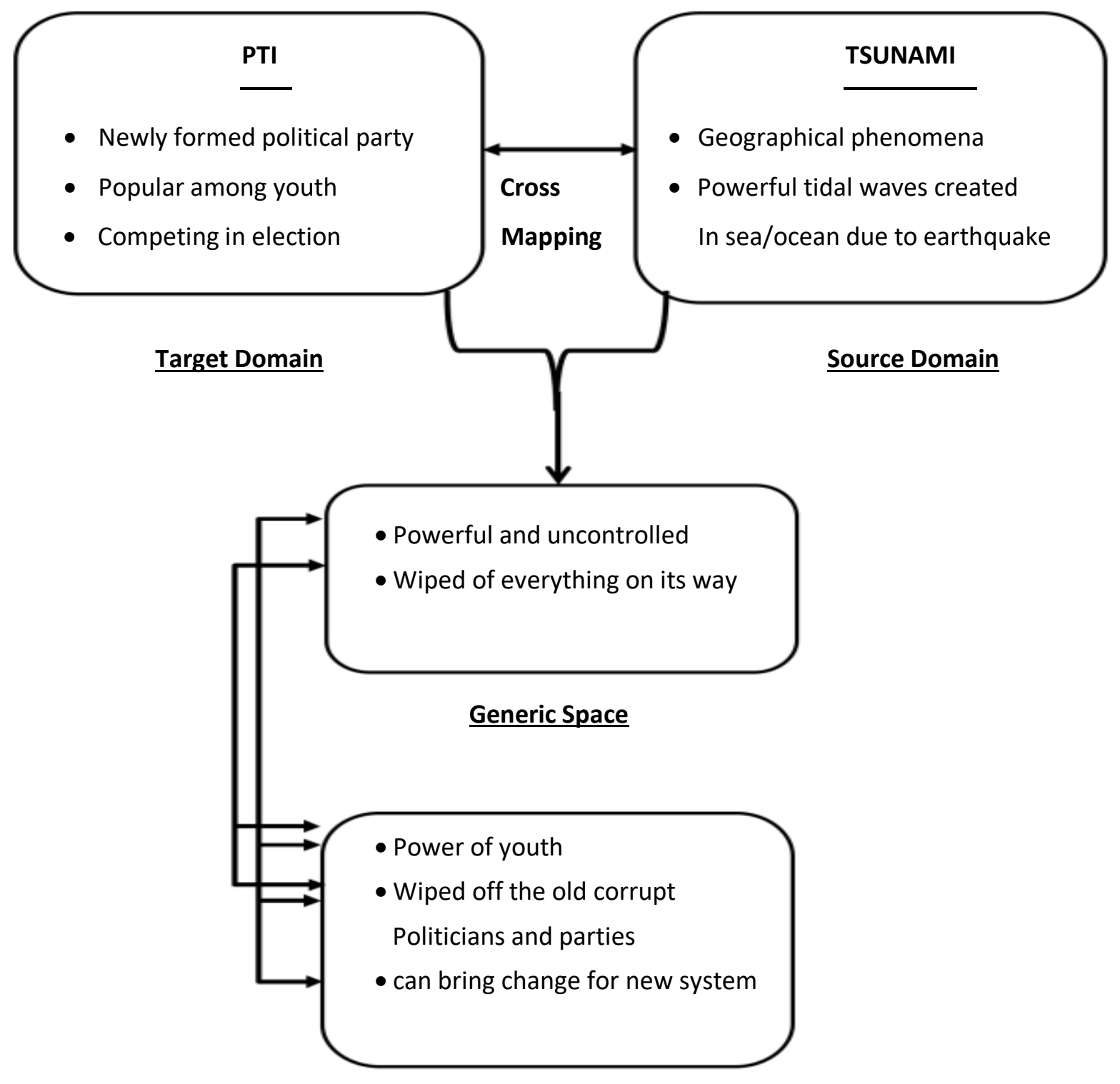

Blend 


\subsection{Corruption metaphor}

In Pakistani society, corruption is one of major social issue. PTI highlights the main socio-economic problems and challenges faced by the country due to weak leadership of ruling parties. Basic reason for declining economy of the country is the corruption of government and their allies. Imran Khan has mentioned it as a 'cancer' for country. He explained the most serious issue in our society with the help of structural metaphor 'cancer'. He explains the idea through analogical relationship between corruption and cancer. He declares it the root cause of all problems in the country. Corruption is a fatal disease which is cancer. The concept of disease is mapped onto the idea of corruption. Cancer spreads silently in the body and leads to death. Similarly corruption is increasing in the country and affecting the economy of the country. Consequently the idea is completed to hint on the prevailing poverty in the country.

\section{[Sab se barri cancer corruption hai]}

'The biggest cancer is corruption'.

[Corruption mulk ke liye cancer hai. Jise teesri dunya kehtay hain, ghurbat is ki sab se barri waja corruption ki beemari hai.]

'Corruption is a cancer for the country. What is called third world, poverty, the biggest reason of its is the disease of cancer.'

Further elaboration of the generic space is that the germs of corruption are spreading in the country through corrupt and insincere political leaders. These leaders are corrupt therefore they are like germs of the disease cancer which infecting the society. As disease gradually infects the body and making it fragile similarly these thieves (politicians) are taking money out of the country which is harmful for the economic state of the country.

[jis mulk ka leader corrupt hota hai, sadar daakoo hota hai opposition leader chori ker ke arbon ropya bahir ley jata hai us mulk ka koi mistaqbil nahi hota.]

'The country whose leader is corrupt, president is dacoit, opposition leader steals billion of rupees and sends it abroad, that country has no future.'

\subsection{Struggle metaphor}

PTI wants to bring change in Pakistan's socio-economic domain. This change is to make the country prosperous. Novel structure metaphor New Pakistan (Naya Pakistan) is used repeatedly. This New Pakistan is what Muslims of subcontinent dreamt of during 20th century when they were getting independence from British rule and Hindu domination. Pakistan resolution was passed on 23 March 1940 in Lahore. Minar-e-Pakistan was built as a monument of Pakistan resolution. PTI organised a huge public rally at Minar-e-Pakistan and asserts that they want a new Pakistan as what Quaid-e-Azam and Iqbal defined for the Muslins of subcontinent.

The objectives are not achieved yet. Therefore, the struggle for independence is not over. People of Pakistan have to strive to transform and revolutionised the country in the directions given by the Founding Father of the nation.

[aik din mera mulk tayar ho ga woh Pakistan bananay ke liya jo Quaid-e-Azam ka Pakistan hona chaheye tha........] 


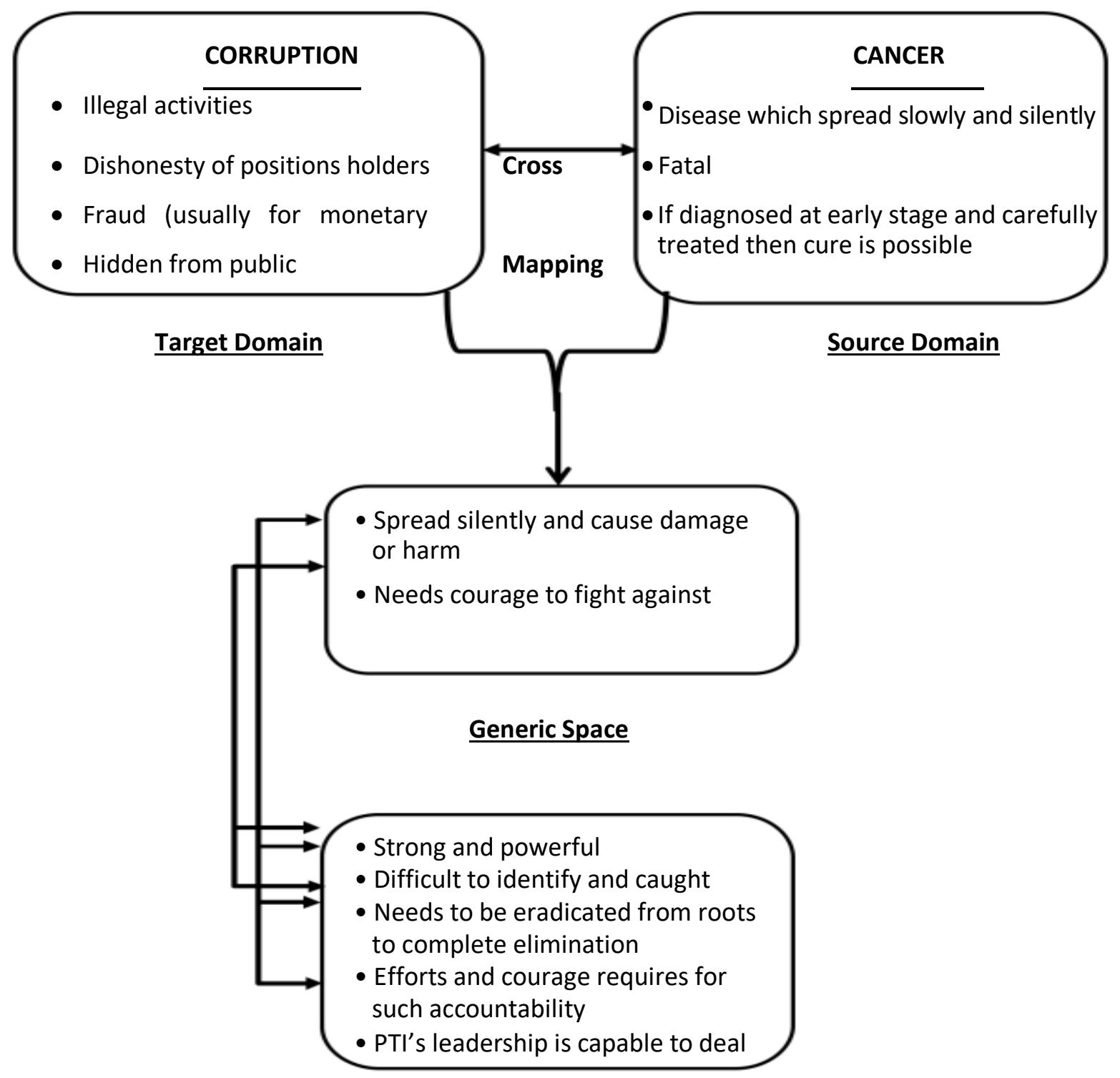

\section{Blend}

'One day my country would be ready to build the Pakistan which should be the Pakistan of Quaid-eAzam.'

The struggle for independence is equated with the political campaign of PTI to bring change. In history, Muslims of subcontinent fought against the rule of British and now Imran Khan wants liberation from the enslavement of America. Those who are the part of this political campaign can tell their children that they were the part of the struggle of 'Naya Pakistan'. So PTI is again making the history and its followers are the part of the history.

[aik din aap apney bachon ko batain gay ke aap aik naye Pakistan ki bunyad rakhne wale logon main se the] 
'You will tell your children that you were the part of the founding people of New

Pakistan.'

Imran Khan asserts that they will bring a new system for the people of Islamic republic of Pakistan. The current system was implemented by British rulers for their slaves. This system supports elite and suppresses the common people. It was meant for slavery. All power and authority is reserved for rulers. But PTI wants to bring this power and authority down to the masses.

[Hum ye nizam badlein gain. Bartania ka nizam ghulamon ke liye tha.] 'We will change the current system. British System was for slaves.'

[Ye mulk Amreeka ki imdad per, us ke paisa per, un ki bheek pen ahi nahi chale ga. Bheek nahi mangain gai] [Amrica ki ghulami nahi karein gai.]

'This country will not run by the monitory support or charity of America. We will not beg.

We will not be the slaves of America'.

Imran Khan declares that Pakistan got independence from British Rule but this is not freedom in true sense. Pakistan is now the slave of America. The leader of PTI takes 'economic dependency as slavery'. PTI will follow the policy of self-reliance like free independent nations.

Imran Khan announces that he will rely on their own power to generate resources. Next metaphoric expression supports the same concept as:

[Ehad kerte hain hamesha apne quwat-e-bazoo per inhesar Karen gein. ] 'We commit that we will rely on strength of our own arms.'

\section{Existing Pakistan}

- Deteriorating Social, economic situation

- Corruption, energy crisis, poor law \& order

- Change the system of injustice with justice \& equality

- Taking foreign aid \& following their direction

\subsection{Sports metaphors}

Chairman of PTI is an ex-cricketer of Pakistan. Many novel metaphors related to sports have been used throughout the political drive of PTI. He uses the novel metaphor of 'cricket match' for political contest. PTI visualises that as a captain Imran Khan is an experienced and trained player. He can play well and can lead his team to right direction. He is equally capable of winning the match. Pakistan election 2013 is like a cricket match that is played between PTI and opponent party PML (N).

[Match shuru hone wala hai. Barra zabardast match ho ga ......] 'Match is going to be started.

That will be a great match.'

[Cricket main sirf dou innings hoti hain. Ye tou panch panch innings le chuke hain aur kitni barian leni hain. Apni barian zaya ker din, mulk ko kuch nahi dia sirf apni tajorian bharin. Aap to maych haar jain gai.]

'There are two innings in test cricket. They have played five innings and how many turns they want. Their performance was poor. Country has get nothing but they've got the big bank balance. You will lose the match.'

In cricket, there are one-day international and test matches. Imran Khan equates the ruling of the country as playing a test match. The performance of the government is like playing the inning of the test match. The performance of the first inning is crucial as it supports the victory of the team in the second innings. If the team scores good in first innings they will lead in the second innings and can 
ultimately win the match and vice versa. The one-to-one encounter of PTI and PML (N) is a cricket match. Both parties are like cricket teams. Winning an election and taking a specified time period of rule that is 5 years, is like playing a test match.

\section{Conclusion}

The Chairman PTI, Imran Khan, represents his progressive vision about the future of Pakistan. He evokes the basic ideology and history of the creation of the country. He uses metaphors related with the source domain of sports, culture and physical environment. First of all, PTI has to convince the public why there is a need to rebuild the nation or 'Naya Pakistan' (New Pakistan). Then, the Chairman PTI should focus on how PTI will practically achieve these targets. Imran Khan calls his party 'the party of youth'. He uses the metaphors 'tsunami' for the force of youth. PTI will bring about change in the country through 'tsunami' for which young people are working. He assigns the title of 'Tabdeeli Razakar' (volunteers of changes) to these young girls and boys and advises them to spread the message of PTI to every nook and corner of the country. Chairman PTI asserts that the root cause of all problems is corruption. He uses the metaphor 'cancer' for corruption.

PTI uses novel metaphors to represent their ideology, strategy and future plans. He expresses his strategies and future plans through correlation to the ideologies and discernment of the leaders of the independence movement. Chairman of PTI, Imran Khan, evokes the basic ideology and history of the creation of the country. He shares his political world views with masses on the basis of shared cultural norms and values. It also helps him to establish a close relationship and association with the members of the Pakistani society.

\section{References}

Ankersmit, F. (1994). History and tropology: the rise and fall of metaphor. Berkeley, CA: University of California Press.

Black, M. (1993). More about metaphor. In A. Ortony (Ed.), Metaphor and thought (pp. 19-41). Cambridge, UK: Cambridge University Press.

Bucholtz, M. (2004). Language and ideology. In A. Durranti (Ed.), A companion to linguistic anthropology (pp. 369-94). Oxford, UK: Blackwell Publishing Ltd.

Cameron, L. (1999). Researching and applying metaphor. Cambridge, UK: Cambtidge University Press.

Cazeaux, C. (2007). Metaphor and continental philosophy. London, UK: Routledge.

Cohen, J. (1993). The semantics of metaphor. In A. Ortony (Ed.), Metaphor and thought (pp. 58-70). Cambridge, UK: Cambridge University Press.

Danesi, M. (2004). A basic course in anthropological linguistics. Toronto, ON: Canadian Scholars' Press Inc.

Duranti, A. (1997). Linguistic anthropology. Cambridge, UK: Cambridge University Press.

Fauconnier, G. (1997). Mapping in language and thought. Chicago, IL: Cambridge University Press.

Ferdenanz, J. W. (1974). The mission of metaphor in expressive culture. Current Anthropology, 15, 119-146.

Foley, W. A. (1997). Anthropological linguistics: an introduction. Oxford, UK: Black Well Publishers Ltd.

Guttenplan, S. (2005). Objects of metaphor. Oxford, UK: Clarendon Press.

Kovecses, Z. (2000). Metaphor and emotion - language, culture and body. Chicago, IL: Cambridge University Press. 
Malik, A. R., (2020). Metaphors in political campaigning - An anthropological linguistics perspective. Global Journal of Sociology: Current Issues. 10(2), 40-50. https://doi.org/10.18844/gjs.v10i2.4753

Kovecses, Z. (2010). Metaphor - a practical introduction. New York, NY: Oxford University Press.

Lakoff, J. (1987). The cognitive model of anger inherent in American English. In D. Holland (Ed.), Cultural models in language and thought (pp. 195-221). New York, NY: Cambridge University Press.

Lakoff, J. (1990). Metaphor we live by. Chicago, IL: Chicago Publishing Press.

Leezenberg, M. (2001). Contexts of metaphor. London, UK: Elsevier.

Levin, S. R. (1993). Language, concepts, and words: three domains of metaphor. In A. Ortony (Ed.), Metaphor and thought (pp. 112-123). New York, NY: Cambridge University Press.

Ortony, A. (1993). Metaphor and thought. New York, NY: Cambridge University Press.

Overing, J. (2000). Social and cultural anthropology: the key concepts. London, UK: Routledge.

Pennink, B. \& Jonker, J. (2010). The essence of research methodology a concise guide for master and Ph. D students. London, UK: Springer. 